\title{
BIOETHANOL PRODUCTION FROM SEAWEED PROCESSING WASTE BY SIMULTANEOUS SACCHARIFICATION AND FERMENTATION (SSF)
}

\author{
Andi Hakim $^{1 *}$, Ekowati Chasanah' ${ }^{2}, \mathrm{Uju}^{1}$, and Joko Santoso' \\ ${ }^{1}$ Departement of Aquatic Product Technology, Bogor Agricultural University, \\ Jalan Lingkar Akademik Kampus IPB Dramaga, Bogor 16680, Indonesia \\ ${ }^{2}$ Research Center for Marine and Fiseheries Product Processing and Biotechnology, \\ Jalan KS Tubun Petamburan VI, Slipi, Central Jakarta 10260, Indonesia \\ Article history: \\ Received: 3 April 2017; Revised: 17 June 2017; Accepted: 28 July 2017
}

\begin{abstract}
Seaweed processing waste has been used for bioethanol production through simultaneous saccharification and fermentation (SSF). SSF is commonly used for bioethanol production to shorten the process and to increase the yield of ethanol produced by Trichoderma reesei and Saccharomyces cerevisiae. The aim of this research was to obtain the best concentration of $T$. reesei and S. cerevisiae to produce bioethanol by SSF. The concentration of $T$. reesei and S. cerevisiae used was 0 (control), 5, 10, 15 and $20 \%(\mathrm{v} / \mathrm{v})$. The SSF process was carried out by using shaking incubator at $35{ }^{\circ} \mathrm{C}$ and rotation of $150 \mathrm{rpm}$ for 3 days. The untreated and hot water treated seaweed processing waste used in this study have moisture content values of $12.94 \pm 0.08 \%$ and $15.38 \pm 0.19 \%$, ash content values of $16.72 \pm 0.08 \%$ and $18.39 \pm 0.19 \%$, lignin content values of $15.38 \pm 0.11 \%$ and $12.74 \pm 0.38 \%$, and cellulose content values of $26.92 \pm 0.57 \%$ and $34.57 \pm 0.81 \%$, respectively. The result of SSF process of seaweed processing waste showed that different concentrations of $T$. reesei and S. cerevisiae (control, 5, 10, 15 and 20\%) yielded significant effect $(p<0.05)$ on the total reducing sugars and ethanol produced. The Duncan Multiple Range Test (DMRT) showed that the treatment $10 \%$ of $T$. reesei and S. cerevisiae concentration in the seaweed processing waste treated with hot water was the best treatment producing highest yield of ethanol.
\end{abstract}

Keywords: bioethanol, pretreatment, seaweed processing waste, SSF

\section{Introduction}

Seaweed is one of aquatic commodities which is abundantly available and useful material for feedstock, food industries, cosmetics and pharmacy. Based on the Food and Agricultural Organization of the United Nations (2017) the global data of seaweed and water plants volume reached 30.4 million tons in 2015 . The Indonesian seaweed production in 2014 reached 10.2 million tons and increased by $10.83 \%$ in 2015 (Ministry of Marine Affairs and Fisheries of Indonesia, 2015). Seaweed is very rich in carbohydrate source ranging from $20-72 \%$ (Nahak et al., 2011; Juneja, Ceballos, \& Murthy, 2013). The carbohydrate contents of seaweed are varied which is composed of hydrocolloid and hemicellulose, and cellulose with different content depending on the types of seaweed. Agar is one of hydrocolloid compounds produced by seaweed.
Nowadays, there are numerous agar industries in Indonesia producing solid waste. One of the prospective products from seaweed processing waste utilization of industrial agar is the bioetanol production.

The processing waste of agar industry contains $30.18 \%$ cellulose, $13.87 \%$ hemicellulose and $5.76 \%$ lignin (Andhikawati, 2014). Lignocellulose from seaweed has a low lignin content, making it easier for bioethanol production (Wei, Quertermen, \& Jin, 2013). Conversion of lignocellulose biomass into bioethanol is conducted through several stages, namely the initial processing of lignocellulosic biomass (pretreatment), the saccharification process using enzymes, and the fermentation process (Borines, Leon, \& Cuello, 2013). El-Naggar, Deraz, \& Khalil (2014) reported that the optimum condition for bioethanol production from lignocellulose is strongly influenced by raw materials,

${ }^{*}$ Corresponding author.

E-mail: hakim.seribu@gmail.com 
the type of degradation microorganism and the fermentation condition.

Pretreatment is performed to decrease lignin levels that can inhibit the process of saccharification. Martosuyono, Hakim, \& Fawzya (2015) reported that $4-5 \% \mathrm{NaOH}$-pretreated seaweed solid waste contained $5.30 \%$ and $3.86 \%$ lignin; and $26.31 \%$ and $24.85 \%$ of cellulose. Other research using liquid hot water for pretreatment process at $121^{\circ} \mathrm{C}$ was reported by Pasanda, Azis, \& Kusuma (2016) on seaweed waste with lignin content $0.64 \%$. The lignin content was decreased by pretreatment using hot water at high temperature that the seaweed waste more easily processed by enzymatic treatment on the saccharification and the fermentation process. The method of pretreatment using hot water has the advantages to more economical and environmentally responsible.

The production of bioethanol from seaweed has been reported using Gelidium sp. (Kim, Wi, Jung, Song, \& Bae, 2015), Gracilaria sp. (Adini, Kusdiyantini, \& Budiharjo, 2015), Padina tetrastromatica (Ashokkumar et al., 2017) and seaweed waste (Pasanda, Azis, \& Kusuma, 2016). Uju et al. (2015) reported the enzymatic saccharification from carrageenan industrial waste with parecetic acid (PPA) and ionic liquid (IL) converted the cellulose by $91 \%$. Production of bioethanol from Gelidium amansii with simultaneous saccharification and fermentation (SSF) using $\beta$-glucosidase and $S$. cerevisiae at $37^{\circ} \mathrm{C}, \mathrm{pH} 4.8$ for 48 hours yielded $84.9 \%$ bioethanol (Kim et al., 2015). Simultaneous saccharification and fermentation (SSF) is a method that combines two stages into one phase to shorten the processing time and to increase the yield of bioethanol produced. The process is more efficient because two reactions occur simultaneously, the conversion of cellulose into sugars and the conversion of sugar into bioethanol through the fermentation process by using cellulase enzyme and yeast (ElNaggar, Deraz, \& Khalil, 2014).

This study aims to convert seaweed processing waste into bioethanol production using SSF method through the application of $T$. reesei and S. cerevisiae.

\section{Materials and Methods}

\subsection{Characterization of Seaweed Processing Waste}

The seaweed solid waste was taken from small scale agar processing unit in Pameungpeuk, District of Garut, West Java. The fresh processing waste material was sun dried and grounded to size 60 mesh prior to pretreatment. The hot water treatment of seaweed processing waste were carried out at $121^{\circ} \mathrm{C}$ for 30 minutes. The ratio of seaweed processing waste : water was $1: 5$ ( $1 \mathrm{~g}$ of sample added by $5 \mathrm{~mL}$ of water) (Pasanda, Azis, \& Kusuma, 2016). The sample of seaweed processing waste was analyzed for the cellulose and lignin content by Chesson method (Datta, 1981), water content by SNI 03-1971-1990, $\mathrm{NaCl}$ content by SNI 01-2359-1991, the characteristic of seaweed processing waste was analyzed using Scanning Electrone Microscope (Zeiss EVO MA 10) and Fourier-Transform Infrared Spectroscopy (PerkinElmer Spectrum One). The seaweed processing waste and cellulose standard (Avicel-Sigma) was analysed at 4000 to $800 \mathrm{~cm}^{-1}$.

\subsection{Saccharification and Fermentation}

The SSF process was conducted following methods of Tan \& Lee (2014), that convert carbohydrate in the waste into ethanol using $T$. reesei and $S$. cerevisiae $(1: 1)$ in different concentrations. Preparation of $T$. reesei and $S$. cerevisiae cultures was performed using PDB (Potato Dextrose Broth) medium at $35^{\circ} \mathrm{C}$ at $120 \mathrm{rpm}$ for 48 hours using shaking incubator.

Control (0), $5,10,15$, and $20 \%$ of inoculum starter $(\mathrm{v} / \mathrm{v})$ and $50 \mathrm{mM}$ citrate buffer $(\mathrm{pH} 4.8)$ were added into the substrate. The SSF was performed using shaking incubator at $35^{\circ} \mathrm{C}, 150 \mathrm{rpm}$ for 72 hours. To determine the best concentration of substrate, sampling at 0, 24, 48 and 72 hours was conducted for the analysis of reducing sugar and ethanol content. The sample was centrifugated at $10,000 \times \mathrm{g}$ for 15 minutes before conducting the analysis. All experiments were conducted in triplicates unless otherwise stated.

Sugar concentration was measured by reacting the saccharification product with 3.5-dinitrosalycilic acid (DNS) and measured the absorbance at $575 \mathrm{~nm}$ (Miller, 1959). The $\mathrm{pH}$ value are measured using $\mathrm{pH}$ meter (SNI 06-6989.11-2004). The ethanol content from saccharification and fermentation process was measured using Gas Chromatography (GC-FID Agilent Technologies 7890A). The standard ethanol curve was prepared by the area and ethanol concentration of 0.1 , $0.3,0.5,0.8,1.0$ and $1.2 \%(\mathrm{v} / \mathrm{v})$. The ethanol content from SSF process was measured by interpolation from the standard curve.

The data were analyzed using Completely Randomized Design (CRD) with 2 factor experiments. The $1^{\text {st }}$ factor is the treatment of seaweed processing waste. The $2^{\text {nd }}$ factor is the concentration of $T$. reese $i$ and $S$. cerevisiae. This treatment was analyzed using Analysis of Variance (ANOVA). Treatment at the determination stage of culture concentration that gives 
Table 1. Characteristics of seaweed processing waste

\begin{tabular}{ccccccc}
\hline \multirow{2}{*}{$\begin{array}{c}\text { Seaweed } \\
\text { processing waste }\end{array}$} & \multicolumn{7}{c}{ Concentrations (\%) } \\
\cline { 2 - 7 } & Cellulose & Hemicellulose & Lignin & Ash & Moisture & NaCl \\
\hline SWU & $26.92 \pm 0.57$ & $16.11 \pm 0.05$ & $15.38 \pm 0.12$ & $16.72 \pm 0.11$ & $12.94 \pm 0.06$ & $3.77 \pm 0.07$ \\
SWT & $34.57 \pm 0.81$ & $13.99 \pm 0.23$ & $12.74 \pm 0.38$ & $18.39 \pm 0.19$ & $15.38 \pm 0.13$ & $1.41 \pm 0.11$
\end{tabular}

Note: SWU: Untreated Seaweed processing waste; SWT: Seaweed processing waste pretreated with hot water

a significant $(p<0.05)$ on ethanol content will be tested further with Duncan Multiple Range Test (DMRT) using SPSS 17.0 software.

\section{Results and Discussion}

\subsection{Characteristics of Seaweed Processing Waste}

The chemical composition of seaweed processing waste is shown in Table 1. Lignin, hemicellulose and cellulose content of untreated seaweed processing waste (SWU) were $15.38 \%, 16.11 \%$ and $26.92 \%$, and seaweed processing waste treated with hot water (SWT) were $12.74 \%, 13.99 \%$ and $34.57 \%$ respectively. The high content of lignin in seaweed processing waste was affected by various types of seaweed that are used as raw materials in the small scale agar industry in Pamengpeuk, Garut, West Java. Mixture of seaweed such as Gracilaria sp. and Gelidium sp. is usually used in the processing of agar. However, the content of lignin and hemicellulose was decreased after treatment with hot water.

Cellulose content of seaweed processing waste increased from $26.92 \%$ to $34.57 \%$ after hot water pretreatment at $121^{\circ} \mathrm{C}$. Cellulose content of seaweed processing waste used in this study was higher than that of reported by Sari, Sugiyono, \& Assadad (2013), i.e $20.17 \pm 0.03 \%$ (Gracilaria sp.). Pasanda, Azis, \& Kusuma (2016) reported that the treatment of seaweed waste with liquid hot water decreasing the lignin content from $4.24 \%$ to $0.64 \%$ and increasing the cellulose content from $18.98 \%$ to $21.35 \%$. Hot water treatment might cause changes of cellulose content of the seaweed waste by partially dissolving lignin and hemicellulose in the seaweed processing waste.

Cellulose contents in seaweed processing waste that can be converted into sugars for bioethanol production, increased to $34.57 \%$ from $26.92 \%$ after hot water treatment. The moisture, ash and $\mathrm{NaCl}$ content of untreated seaweed processing waste were $12.94 \pm 0.08 \%, 16.72 \pm 0.16 \%$ and $3.77 \pm 0.07 \%$ respectively, while after the pretreatment using hot water were $15.38 \pm 0.18 \%, 18.39 \pm 0.28 \%$ and
$1.41 \pm 0.11 \%$, respectively. Hot water treatment was causing moisture and ash contents to increase, affecting enzyme activity converting cellulose into sugar and then ethanol. In contrast, the $\mathrm{NaCl}$ in the sample dissolved due to the hot water treatment so that the $\mathrm{NaCl}$ content decreased. The $\mathrm{NaCl}$ content affected the microbial activity and growth to be inhibited during bioethanol production in the SSF process. High content of salts will retard the microbes used in this fermentation process.

Scanning Electron Microscope (SEM) was used to observe microstructures of cellulose and lignin in the seaweed processing waste before and after treatment. The difference in cellulose structure of untreated seaweed processing waste and treated with hot water was shown in Figure 1. The structure of cellulose (cellulose bonds with lignin) after hot water treatment became more rug and loose. The treatment with hot water caused swelling, breaking the bond between lignin and carbohydrate, increasing cellulose surface and decreasing polymerization and crystallinity levels. All of these effects make cellulose more accessible for enzymatic fermentation, and ultimately can improve the efficiency of bioethanol production (Zhang et al., 2013). Pasanda, Azis, \& Kusuma (2016) reported that the use of hot water treatment caused the shape of the inner surface of the seaweed waste became more clearly, confirming by changes in cellulose structure. The inside of the parenchyma cells become increasingly apparent as shown in Figure 1. This is possible due to the loss of wax or lignin in microfibril. The structure of the seaweed processing waste changed after treatment with hot water, and was able to increase the surface area that was easily accessible for enzymatic hydrolysis.

The characteristics of seaweed processing waste was also analyzed with Fourier-Transform Infrared Spectroscopy (FTIR) using infrared spectrum. According to Stevulova et al. (2014), peak at wavelength $2800-3400 \mathrm{~cm}^{-1}$ indicates polysaccharides, $1300-1400 \mathrm{~cm}^{-1}$ indicates cellulose, 1028 and 1733 $\mathrm{cm}^{-1}$ shows hemicellulose groups, whereas wavelength $1500-1600 \mathrm{~cm}^{-1}$ shows a lignin group. Figure 2 shows that the standard FTIR spectrum of cellulose and the 


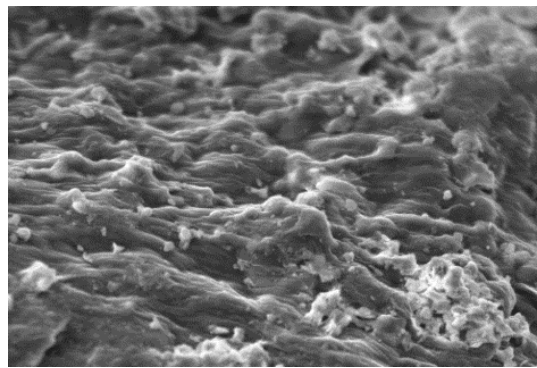

$1000 \times(a)$

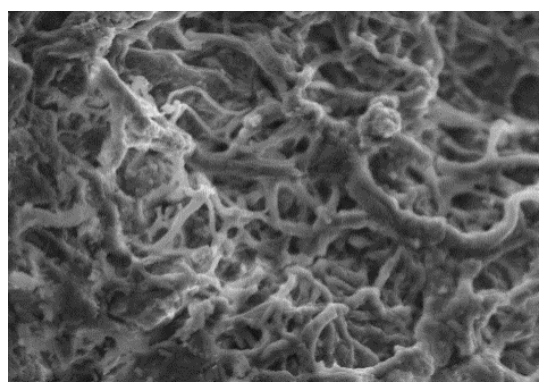

$1000 x(b)$

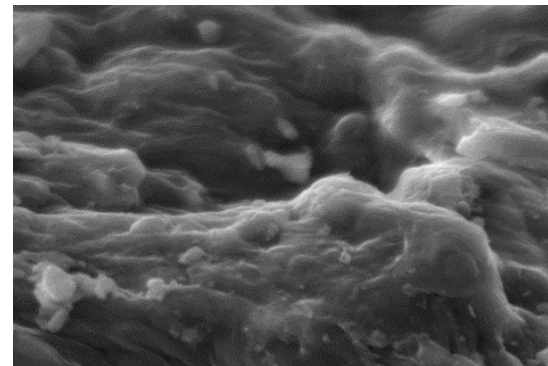

$3000 \times(a)$

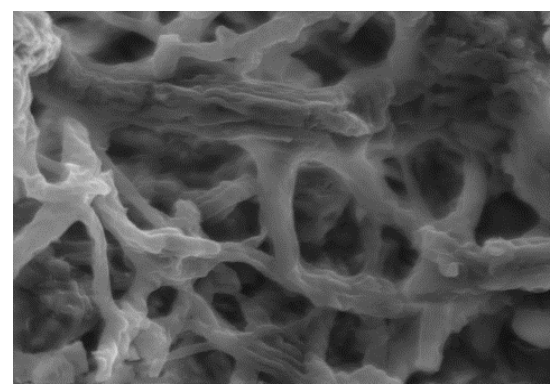

$3000 x(b)$

Figure 1. Scanning Electrone Microscopy of untreated seaweed processing waste (a) and treated with hot water (b).

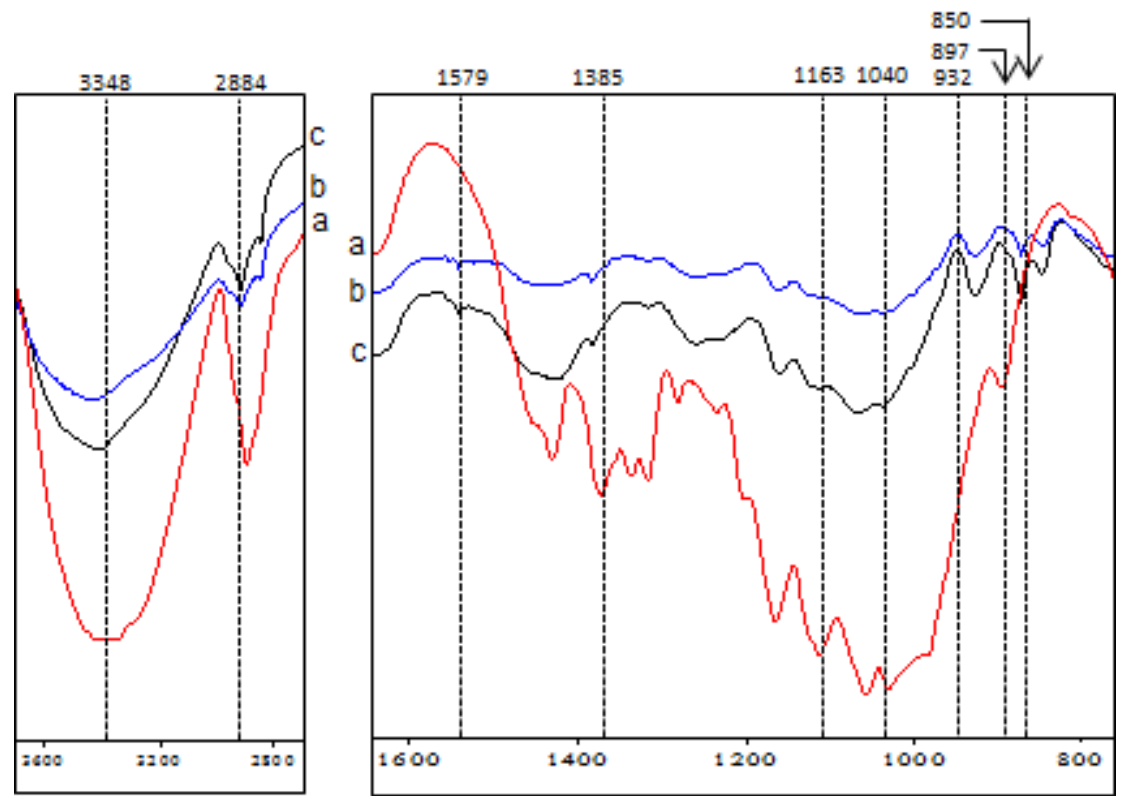

Figure 2. Fourier-Transform Infrared Spectroscopy of (a) cellulose standard (b) untreated seaweed processing waste and (c) treated with hot water.

waste looks similar. The FTIR spectrum of cellulose standard and seaweed processing waste show the presence of crystalline cellulose groups at wavelengths of $1385 \mathrm{~cm}^{-1}$. The lignin group was seen in the untreated and hot water treatment seaweed processing waste at wavelength $1579 \mathrm{~cm}^{-1}$. Uju et al. (2015) reported that the high cellulose crystallinity characteristics in the untreated and PAA-pretreated of seaweed waste biomass from the carrageenan industry were indicated by a strong and sharp peak appearance at $1425 \mathrm{~cm}^{-1}$ but a weak appearance at $897 \mathrm{~cm}^{-1}$. The results suggests that the hot water treatment caused the pretreated seaweed waste changes to more amorphous fractions. Sharp large peaks are visible from 3000 to $3600 \mathrm{~cm}^{-1}$, which indicates $\mathrm{OH}$ stretching. These peaks were centered at $3348 \mathrm{~cm}^{-1}$. Its a weakening of the hydrogen bonds occurred in the cellulose structure. Nurhayati \& Kusumawati (2014) reported that the cellulose spectrum from the seaweed processing waste 


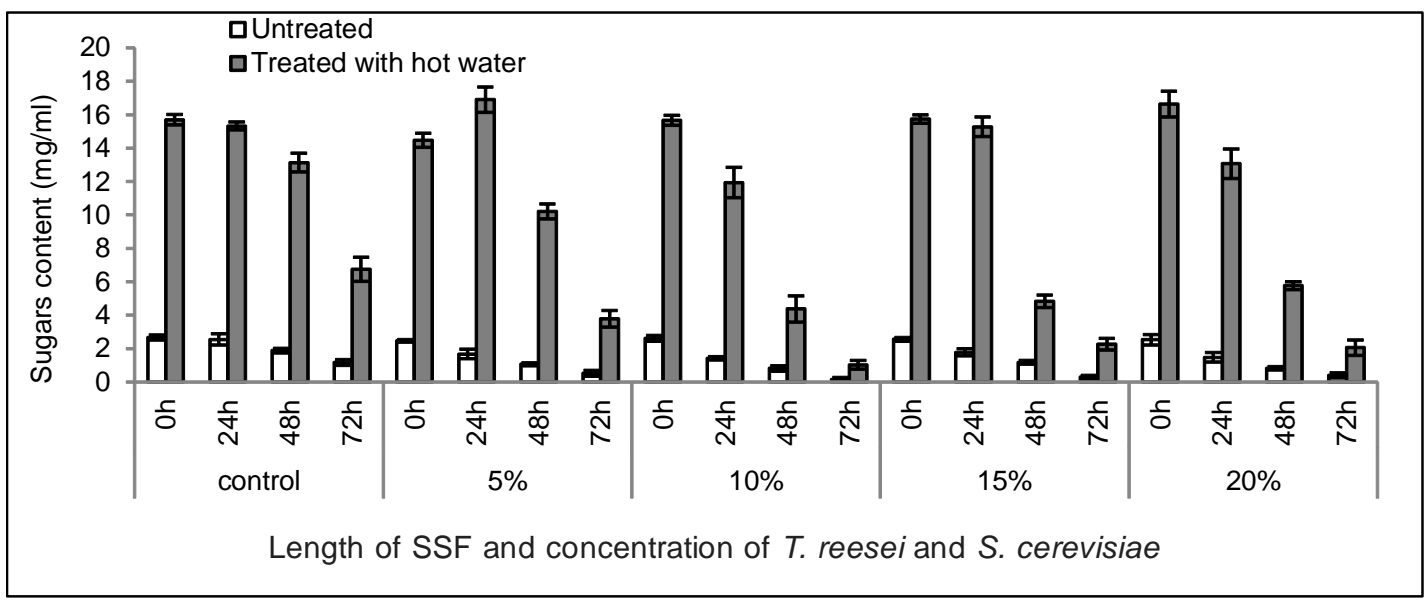

Figure 3. Total reducing sugars of seaweed processing waste.

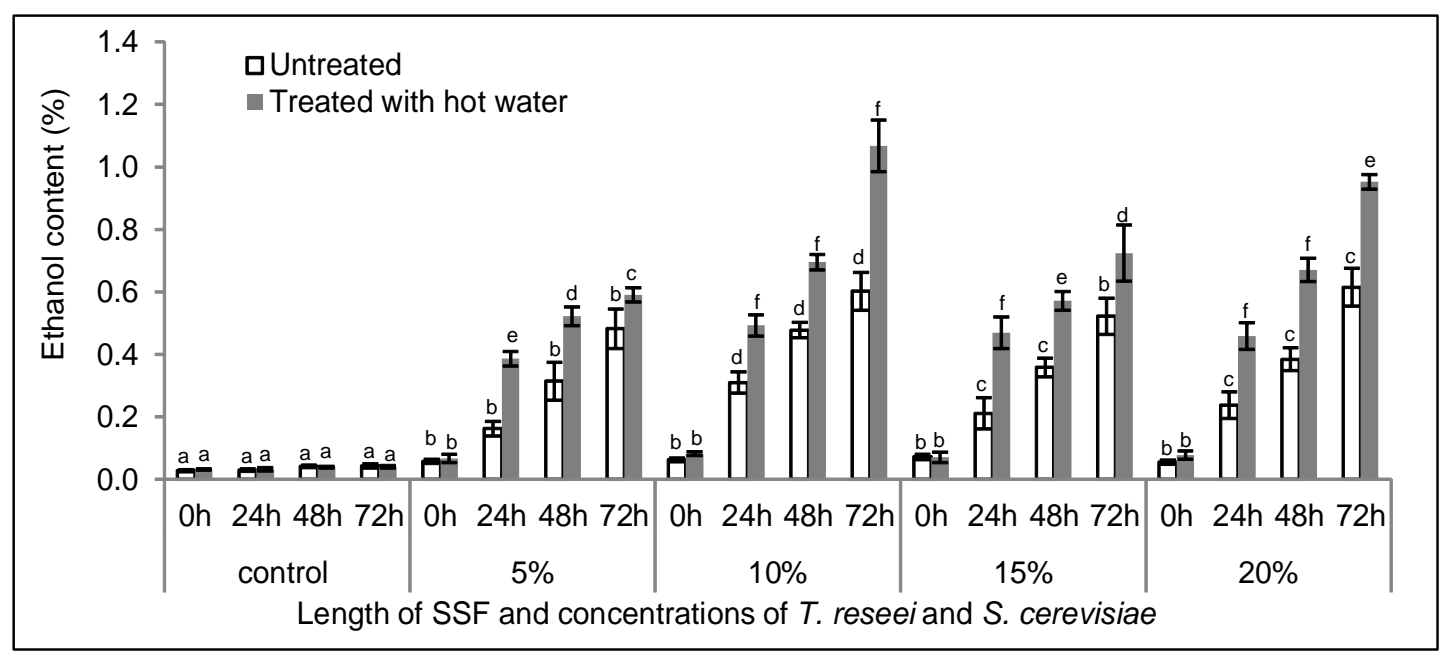

*Different notation indicates a significant $(p<0.05)$ between treatments at the same time

Figure 4. Ethanol contents of seaweed processing waste.

appeared in the absorption areas of 1430 and 1638 $\mathrm{cm}^{-1}$.

\subsection{Bioethanol Production by SSF}

\subsubsection{Total reducing sugars}

The profiles of total reducing sugars of simultaneous saccharification and fermentation of seaweed processing waste used $T$. reesei and $S$. cerevisiae are shown in Figure 3 . The reducing sugars were the result of cellulose hydrolysis in the saccharification process with $T$. reesei. The reducing sugar produced will be used by $S$. cerevisiae as fermentation substrate in bioethanol production. The total reducing sugars produced was $2-16 \mathrm{mg} / \mathrm{mL}$ in seaweed processing waste treated with hot water (SWT), while the untreated seaweed processing waste (SWU) ranged from $0.3-2.7 \mathrm{mg} / \mathrm{mL}$. The decreased of lignin content and high cellulose content in the seaweed processing waste treated with hot water affected the total reducing sugar produced.

Different concentrations of $T$. reesei and $S$. cerevisiae (control, 5, 10, 15 and 20\%) had a significantly different effect on total reducing sugars produced $(p<0.05)$. The total reducing sugars in this study were able to release $16 \mathrm{mg} / \mathrm{mL}$, higher than that of Sari, Sugiyono, \& Assadad (2013) which value was released $10.77 \mathrm{mg} / \mathrm{mL}$ using raw materials of industrial seaweed waste (Gracilaria sp.). The incubating time $(0,24,48$ and 72 hours) had a significantly different effect on total reducing sugars produced $(p<0.05)$. The high total reducing sugars at beginning of incubation ( 0 hour) showed that hydrolysis in the seaweed processing waste and increased at 24 hours by addition of $T$. reesei and $S$. cerevisiae. The total reducing sugars decreased 
during incubation of simultaneous saccharification and fermentation (SSF) after 24 hours of incubation. The sugar produced directly converted into ethanol. The reducing sugar became an important element as a carbon source for $S$. cerevisiae growth in the bioethanol production (Adini, Kusdiyantini, \& Budiharjo, 2015).

\subsubsection{Ethanol content}

Seaweed processing waste became one of the potential feedstock in bioethanol production because it has high cellulose content. The conversion of seaweed processing waste to produce ethanol was carried out by SSF at different concentration of $T$. reeseiand S. cerevisiae. Figure 4 shows the ethanol content from the SSF process of seaweed processing waste using $T$. reesei and $S$. cerevisiae. The production of bioethanol from seaweed processing waste through SSF using different concentrations of T. reesei and S. cerevisiae (control, 5, 10, 15 and $20 \%$ ) gave a significantly different effect on ethanol content per time $(p<0.05)$. T. reesei produced cellulase that converted cellulose in the seaweed processing waste becoming sugar which was subsequently converted on to ethanol by $S$. cerevisiae.

Ethanol contents increased with the incubation time of saccharification and fermentation. Increasing levels of ethanol are affected by total reducing sugars produced during the process of SSF. The highest ethanol content was generated from seaweed processing waste treated with hot water for 72 hours of SSF with $10 \%$ T. reesei and S. cerevisiae concentrations, resulting ethanol of $1.068 \pm 0.082 \%$ $(\mathrm{v} / \mathrm{v})$. While the ethanol content in untreated seaweed processing waste was $0.615 \pm 0.061 \%(\mathrm{v} / \mathrm{v})$ with the $20 \%$ of $T$. reesei and S. cerevisiae concentration (Figure 4).

Seaweed processing waste treated with hot water and untreated one showed a significant effect on the resulting ethanol content $(p<0.05)$. The ethanol content of seaweed processing waste treated with hot water (SWT) was higher than the untreated seaweed processing waste (SWU). The high content of cellulose and total reducing sugars produced on saccharification was thus affecting the ethanol yield. Sari, Sugiyono, \& Assadad (2013) reported that the ethanol content of industrial seaweed waste for fermentation (Gracilaria sp.) using $T$. viride and $S$. cerevisiae was $0.47 \pm 0.08 \%$. Based on DMRT test, the SSF process using 10\% concentration of $T$. reesei and $S$. cerevisiae was the optimum concentration based on the ethanol content produced on the seaweed processing waste with the pretreatment of hot water. Wahono et al. (2015) reported that the sugarcane bagasse produced ethanol
$0.7485 \%$ after 5 days of incubation by SSF method using the cellulose enzyme $T$. reesei and $S$. cerevisiae.

\section{Conclusion}

The untreated seaweed processing waste and hot water treated waste used for this study had moisture contents of $12.94 \pm 0.08 \%$ and $15.38 \pm 0.19 \%$, ash contents of $16.72 \pm 0.08 \%$ and $18.39 \pm 0.19 \%$ and $\mathrm{NaCl}$ contents of $3.77 \pm 0.07 \%$ and $1.41 \pm 0.11 \%$, respectively. The treatment of seaweed waste with hot water decreasing the lignin content from $15.38 \%$ to $12.74 \%$ and increasing the cellulose content from $26.92 \%$ to $34.57 \%$. The simultaneous saccharification and fermentation process using $T$. reeseiand $S$. cerevisiae for 72 hours resulted in total reducing sugar content of $16 \mathrm{mg} / \mathrm{mL}$ and $1.08 \%$ ethanol content. Based on DMRT showed that the treatment with $10 \%$ of $T$. reesei and $S$. cerevisiae concentration on seaweed processing waste treated using hot water was the optimum treatment to obtain the highest yield of ethanol produced.

\section{Acknowledgement}

This study was funded by Indonesian Endowment Fund for Education, the Ministry of Finance, and supported by the Research Center for Marine and Fisheries Product Processing and Biotechnology, the Ministry of Marine Affairs and Fisheries, Republic of Indonesia.

\section{References}

Adini S., Kusdiyantini E., \& Budiharjo A. (2015). Production of bioethanol from seaweed and waste for Gracilaria sp. With different saccharification methods. Bioma. 16(2), 65-75.

Andhikawati A. (2014). Screening and utilization of endophytic caps in the manufacture of bioethanol from agar-processing waste. Thesis. Bogor (ID): Bogor Agricultural University.

Ashokkumar V., Salim MR., Salam Z., Sivakumar P., Chong CT., Elumalai S., Suresh V., \& Ani FS. (2017). Production of liquid bioefuels (biodiesel and bioethanol) from brown marine macroalgae Padina tetrastromatica. Energy conversion and management. 135, 351-361.

Borines MG., Leon RLD., \& Cuello JL. (2013). Bioethanol production from the macroalgae Sargassum spp. Bioresource Technology. 138, 22-29.

Datta R. (1981). Acidogenic fermentation of lignocellulose - acid yield and conversion of components. Biotechnology and bioengineering. 23, 2167-2170. 
El-Naggar NE., Deraz S., \& Khalil A. (2014). Bioethanol production from lignocellulosic feedstocks based on enzymatic hydrolysis: current status and recent development. Biotechnology. 13, 1-21.

FAO. (2017). The state of world fisheries and aquaculture: contributiong to food security and nutrition for all. Food and Agriculture Organization of The United Nations. Rome. Italy.

Juneja A., Ceballos RM., \& Murthy GS. (2013). Effects of environmental factors and nutrient availability on the biochemical composition of algae for biofuels production [Review]. Energies. 6, 4607-4638.

Kim HM., Wi SG., Jung S., Song Y \& Bae HJ. (2015). Efficient approach for bioethanol production from red seaweed Gelidium amansii. Bioresource Technology. 175, 128-134.

Martosuyono P., Hakim A., \& Fawzya YN. (2015). Chemical pretreatment and enzymatic saccharification of seaweed solid waste. Squalen Bulletin of Marine \& Fish Postharvest \& Biotechnology. 10(2), 61-71.

Ministry of Marine Affairs and Fisheries. (2015). Analysis of marine and fisheries data in 2014. Data, Statistics and Information Center of the Ministry of Marine Affairs and Fisheries. Jakarta.

Miller GL. (1959). Use of dinitrosalicylic acid reagent for determination of reducing sugar. Analytical Chemistry. 31(3), 426-428.

Nahak S., Nahak G., Pradhan I., \& Sahu RK. (2011). Bioethanol from marine algae: a solution to global warming problem. Journal of Applied Environtmental and Biological Sciences. 1(4), 74-80.

Nurhayati \& Kusumawati R. (2014). Cellulose acetate synthesis from effluent treatment waste. JPB Fisheries. 9(2), 97-107.

Pasanda OSR., Azis A., \& Kusuma HS. (2016). Utilization of waste seaweed through pretreatment with liquid hot water method and simultaneous fermentation using Bacteria Clostridium thermocellum. Journal of Material Environmental Sciences. 7(7), 2526-2533.

Sari RN., Sugiyono., \& Assadad L. (2013). Optimization of hydrolysis and fermentation process time in bioethanol production from industrial processing waste (Gracilaria sp.). JPB Fisheries. 8(2), 133-142.

Stevulova N., Cigasova J., Estokova A., Terpakova E., Geffert A., Kacik F., Singovszka E., \& Holub M. (2014). Properties characterization of chemically modified hemp hurds. Journal of Materials. 7, 8131-8150.

Tan IS. \& Lee KT. 2014. Enzymatic hydrolysis and fermentation of seaweed solid wastes for bioethanol production: an optimazion study. Energy. 30, 1-10.

Uju, Wijayanta AT., Goto M., \& Kamiya N. (2015). Great potency of seaweed waste biomass from the carrageenan industry for bioethanol production by peracetic acid-ionic liquid pretreatment. Biomass and Bioenergy. 89, 63-69.

Wahono SK., Rosyida VT., Darsih C., Diah Pratiwi, Frediansyah A., \& Hernawan. (2015). Optimization of simultaneous saccharification and fermentation incubation time using cellulose enzyme for sugarcane bagasse on the second-generation bioethanol production technology. Energy Procedia. 65, 331-336.

Wei N., Quarterman J., \& Jin Y. (2013). Marine macroalgae: an untapped resource for producing fuels and chemicals. Trends in Biotechnology. 31(2), 70-77.

Zhang W., Lin Y., Zhang Q., Wang X., Wu D., \& Kong H. (2013). Optimisation of simultaneous saccharification and fermentation of wheat straw for ethanol production. Fuel. 112, 331-337. 